\title{
Burden \& Coping in Caregivers of Persons with Dementia
}

\author{
Dr. Priyajyoti Chakma1, Dr. H. K. Goswami²
}

${ }^{1}$ Registrar, Department of Psychiatry, Agartala Govt. Medical College, Agartala, Tripura West, 7990061

2Prof. \& HOD Department of Psychiatry, Assam Medical College, Dibrugarh, 7860022

\section{ABSTRACT}

Background: Dementia is a serious loss of global cognitive ability in a previously unimpaired person, beyond what might be expected from normal aging. Dementia is often associated with physical, mental and financial burden. Care giving is associated with more psychological complaints \& coping is most often conceptualized as a response to the demands of specific stressful situations.

Aim : To assess the burden in caregiver of persons with dementia and also assess the coping strategies used by the caregivers.

Settings and Design : The study was conducted in the Department of Psychiatry, Assam Medical College \& Hospital, Dibrugarh. The subjects for the study were recruited from the outpatient \& indoor facilities of the department of Psychiatry, Assam Medical College \& Hospital, Dibrugarh. After application of the inclusion and exclusion criteria, $(n=40)$ cases of Dementia and theircaregivers $(n=40)$ were included in the study.

Materials \& Methods : Diagnosis of dementia was done by fourth edition of the Diagnostic and Statistical Manual of Mental Disorders (DSM-IVTR).The tools used were Burden Assessment Schedule by Thara et al15, Assamese version of ways of Coping Questionnaire by Susan Folkman and Richard S. Lazarus 16-17. Statistical analysis was done by using SPSS-20.

Results : The results revealed that level of burden reported by caregivers of dementia patients was high. The most common coping strategies used by caregivers of Dementia patients were confronting coping (72\%), distancing( $45 \%)$, seeking social support(45\%) and self-controlling (45\%).

Conclusion:The various findings in our study evidence that dementia can have serious consequences on families particularly the primary caregivers. Results highlight the importance of improving the mixed coping skills in burdened caregivers.

Keywords : Dementia, caregivers, Burden, Coping strategies

\section{INTRODUCTION}

Dementia (derived from Latin word, dementatus, meaning out of one's' mind) is a serious loss of global cognitive ability in a previously unimpaired person,

\section{Correspondence :}

Dr. Priyajyoti Chakma, Registrar, Department of Psychiatry, AGMC \& GBP Hospital, Agartala 799006, Tripura, India

Phone : 8131043421, Email : pjchakma84@gmail.com beyond what might be expected from normal aging. Although dementia is far more common in the geriatric population (about $5 \%$ of those over 65 are said to be involved) $)^{1}$, it can occur before the age of 65 , in which case it is termed "early onset dementia"2. Dementia is not a single disease, but a non-specific syndrome affecting many cognitive areas - memory, attention, language, and problem solving. Normally, symptoms must be present for at least six months to support a diagnosis ${ }^{3}$. Dementia is the development of multiple cognitive deficits manifested by both 
memory impairment \& impairment of at least one other cognitive domain including language, praxis, gnosis, \& executive functioning ${ }^{1}$

The single strongest risk factor for dementia is increasing age. ${ }^{4}$ Prevalence doubles about every 5 years from about 5-8 percent at age 65 to 70 to 15 to 20 percent at the age 75 to 80 and up to 40 to 50 percent over age 85 . In 2005 , it was estimated that 24.3 million people worldwide were affected with dementia. ${ }^{5}$ In 2013, worldwide dementia is estimated to account for $4.1 \%$ of all DALYs \& $11.3 \%$ of years lived with disability \& $0.9 \%$ of years of life lost.6 In India 1.8 million people have dementia. ${ }^{5}$ Across India, more than 42000 older people studied in eight centers suggest that Ballabgarh and Vellore have the lowest prevalence rates while Trivandrum and Thiropour have the highest rates. Among all North Eastern states, Assam has the highest number of cases with dementia. ${ }^{7-12}$

Dementia is often associated with physical, mental and financial burden and evidence suggests that elderly people with dementia in developing countries do not often utilize health care services, and when they do, the health care system is often ill prepared to provide quality services for dementia. ${ }^{13}$ The stress and burden experienced by many caregivers to the elderly has recently been the focus of considerable research. ${ }^{14}$ Caring for persons affected with dementia is associated with substantial psychological strain as evidenced by high level of stress in caregivers. Care giving is associated with more psychological complaints \& coping is most often conceptualized as a response to the demands of specific stressful situations. From the above discussion it is clear that caregiver burden is quite common in patients with dementia. There is dearth of study on this subject of burden \& coping in caregivers of patients with dementia from North-Eastern part of the country as yet. Hence, the present study is a sincere effort in this direction.

\section{MATERIAL \& METHODS}

The study was done in Assam medical college hospital which is a tertiary care center situated in Dibrugarh. The study subjects were 40 consecutively selected diagnosed cases of Dementia and their caregivers $(n=40)$ from the outpatient \& indoor facilities of the department of psychiatry, the period of the study was one year (June 2012-May 2013).Sociodemographic information was gathered as per prepared standard questionnaire. Ethical approval \& consent of the patients were obtained in the initial portion of the study. Caregiver burden was evaluated by Burden Assessment Schedule (Thara et al), \& Coping strategies were evaluated by Assamese version of ways of Coping Questionnaire (Susan Folkman and Richard S. Lazarus). The aim of the study was to assess the burden in caregiver of persons with dementia\& its socio demographic variation and also assess the coping strategies used by the caregivers.

Inclusion Criteria : a) Those caregivers giving consent to participate in the study b) Duration of illness of at least 1 year c) Caregivers who were 21 or above 21 years of age, living with \& looking after the patient for at least one year prior to the interview d) Patients of both sexes e) Caregivers of both sexes f) Patients fulfilling the Diagnostic and Statistical Manual of Mental Disorders, Fourth Edition (DSMIV-TR) criteria for dementia g) All the subtypes of dementia.

Exclusion Criteria : a) Patients with previous history of functional psychiatric disorder before the onset of dementia b) Mental Retardation c) Mental and behavioral disorders due to substance use d) Caregiver with chronic debilitating physical illness \& a history of past/current psychiatric consultation.

Tools which were used in the study are : a) informed consent form, b) proforma for socio demographic data c) Burden Assessment Schedule (Thara et al) d)Ways of coping questionnaire (Susan Folkman and Richard S. Lazarus).

Burden assessment schedule (BAS, Thara et al, 1998) 
BAS, developed by Thara et al. at the schizophrenia research foundation (SCARF) is based on the principle of ethnographic exploration at Chennai, with support from the W.H.O. South East Asian Regional Office. The BAS reflects the caregivers' perceptions \& provides valuable\& culturally relevant insights to Burden. This is a semi quantitative 40 item scale measuring 9 different areas of objective \& subjective caregiver burden. Each item is rated on a 3 point scale ("not at all", "to some extent" or "very much" with a total score ranging from 40 to 120 with higher score indicating greater burden). In BAS the minimum score is $40 \&$ max score 120 . Therefore for the requirement of the present study, the cut off has been taken as 80 \& those caregivers who scored less than 80 were considered as experiencing lower burden \& those who scored more than 80 were considered as having higher burden to maintain homogeneity within the group..$^{15}$

\section{WAYS OF COPING QUESTIONNAIRE (WOCQ)}

WOCQ (ways of coping questionnaire) was translated to local language (Assamese) WOCQ scales reliability Alpha values for 8 subscales of WOCQ came 0.87, 0.76, 0.91, 0.88, 0.95, 0.89, 0.77, and 0.97 respectively which suggests the statistical reliability of the scale. Ways of coping questionnaire is primarily a research instrument in studies for assessment of coping process. It was developed by Susan Folkman and Richard S. Lazarusin 1980. The questionnaire is designed to identify the thoughts and action an individual has used to cope with a specific stressful encounter. The questionnaire measures total of 8 type of coping strategies namely Confronting coping, distancing, self-controlling, seeking social support, accepting responsibility, escape avoidance, planful problem solving and positive reappraisal. There are total 66 questions in the full questionnaire. There are two methods of scoring the ways of coping questionnaire, raw and relative. The decision as to which set of score to use depends on the information desired. Raw score describe coping effort for each of the eight types of coping, whereas relative score describe the proportion of effort represented by each type of coping. In both methods of coping, individuals respond to each item on a 4-pointLikertscale where "1-indicates "used somewhat", 2- indicates "used quite a bit and 3-indicates "used a great deal". In the raw scoring the raw scores are the sum of the subjects responses to the items that comprises a given type of coping used in a particular encounter. ${ }^{16-17}$

\section{RESULTS}

Table 1: Sociodemographic profile of the dementia cases

\begin{tabular}{|c|c|c|}
\hline $\begin{array}{l}\text { Demographic } \\
\text { Details }\end{array}$ & $\begin{array}{l}\text { No. of } \\
\text { Dementia } \\
\text { Cases }\end{array}$ & Percentage \\
\hline \multicolumn{3}{|c|}{ Age (in years) } \\
\hline $30-39$ & 1 & 2.5 \\
\hline $40-49$ & 6 & 15 \\
\hline $50-59$ & 6 & 15 \\
\hline $60-69$ & 14 & 35 \\
\hline $70-79$ & 10 & 25 \\
\hline$\geq 80$ & 3 & 7.5 \\
\hline \multicolumn{3}{|c|}{ Gender } \\
\hline Male & 25 & 62.5 \\
\hline Female & 15 & 37.5 \\
\hline \multicolumn{3}{|c|}{ Marital Status } \\
\hline Married & 20 & 50 \\
\hline Unmarried & 1 & 2.5 \\
\hline Widow & 5 & 12.5 \\
\hline Widower & 14 & 35 \\
\hline \multicolumn{3}{|c|}{ Educational Status } \\
\hline Illiterate & 13 & 32.5 \\
\hline Primary school & 11 & 27.5 \\
\hline Middle school & 3 & 7.5 \\
\hline High school & 9 & 22.5 \\
\hline Intermediate & 1 & 2.5 \\
\hline $\begin{array}{l}\text { Graduate or } \\
\text { Postgraduate }\end{array}$ & 3 & 7.5 \\
\hline \multicolumn{3}{|c|}{ Duration of Illness } \\
\hline 1-4 years & 27 & 67.5 \\
\hline
\end{tabular}


Burden \& Coping in Caregivers of Persons with Dementia

\begin{tabular}{|c|c|c|}
\hline $\begin{array}{c}\text { Demographic } \\
\text { Details }\end{array}$ & $\begin{array}{c}\text { No. of } \\
\text { dementia cases }\end{array}$ & Percentage \\
\hline 5-8 years & 13 & 32.5 \\
\hline \multicolumn{3}{|c|}{ Religion } \\
\hline Hindu & 38 & 95 \\
\hline Muslim & 2 & 5 \\
\hline \multicolumn{3}{|c|}{ Locality } \\
\hline Rural & 36 & 90 \\
\hline Urban & 3 & 7.5 \\
\hline Semi-urban & 1 & 2.5 \\
\hline
\end{tabular}

As per table 1, 35\% belonged to the age group 60-69 years, 25\% were from 70-79 years age group, $15 \%$ were from $40-49$ years age group, $15 \%$ were from $50-69$ age groups, $7.5 \%$ were $\geq 80$ years of age \& only 2.5\% were from 30-39 years age group. Maximum no of the patients were male $(62.5 \%)$ \& only $37.5 \%$ were female. Most of the patients were married (50\%), followed by widower (35\%), widow $(12.5 \%)$ and only $2.5 \%$ of the cases were unmarried.

As per findings most of the patients were illiterate $(32.5 \%), 27.5 \%$ were educated up to primary school, $22.5 \%$ up to high school, $7.5 \%$ up to middle school \& graduate level and only $2.5 \%$ studied up to intermediate level. Majority of the participants' duration of illness was between 1 to 4 years $(67.5 \%)$, rest had duration of illness between 5-8 years (32.5\%). Most of the cases belonged to Hindu family (95\%) and only $5 \%$ belonged to Muslim family. It is observed that in this study $90 \%$ of the patients were from rural background, $7.5 \%$ from urban background \& only $2.5 \%$ from semi-urban background.

Table 2 : Socio Demographic Profile of the Caregivers

\begin{tabular}{|c|c|c|}
\hline $\begin{array}{c}\text { Age of the } \\
\text { Caregivers } \\
\text { (Years) }\end{array}$ & $\begin{array}{c}\text { Number of } \\
\text { Care Givers }\end{array}$ & Percentage \\
\hline $21-30$ & 9 & 22.5 \\
\hline $31-40$ & 12 & 30 \\
\hline $41-50$ & 7 & 15 \\
\hline $51-60$ & 6 & 17.5 \\
\hline $61-70$ & 5 & 12.5 \\
\hline
\end{tabular}

\begin{tabular}{|c|c|c|}
\hline $\begin{array}{l}\text { Age of the } \\
\text { Caregivers } \\
\text { (Years) }\end{array}$ & $\begin{array}{l}\text { Number of } \\
\text { Care Givers }\end{array}$ & Percentage \\
\hline $71-80$ & 1 & 2.5 \\
\hline \multicolumn{3}{|l|}{ Gender } \\
\hline Male & 26 & 65 \\
\hline Female & 14 & 35 \\
\hline \multicolumn{3}{|l|}{ Marital status } \\
\hline Single & 2 & 5 \\
\hline Married & 38 & 95 \\
\hline \multicolumn{3}{|c|}{ Educational Status } \\
\hline Illiterate & 17 & 42.5 \\
\hline Primary school & 12 & 30 \\
\hline Middle school & 4 & 10 \\
\hline High school & 4 & 10 \\
\hline Intermediate & 1 & 2.5 \\
\hline $\begin{array}{l}\text { Graduate or } \\
\text { Postgraduate }\end{array}$ & 2 & 5 \\
\hline \multicolumn{3}{|c|}{ Duration of Care } \\
\hline $1-4$ years & 27 & 67.5 \\
\hline $5-8$ years & 13 & 32.5 \\
\hline \multicolumn{3}{|l|}{ Religion } \\
\hline Hindu & 38 & 95 \\
\hline Muslim & 2 & 5 \\
\hline \multicolumn{3}{|l|}{ Locality } \\
\hline Rural & 36 & 90 \\
\hline Urban & 3 & 7.5 \\
\hline Semi-urban & 1 & 2.5 \\
\hline Urban & 3 & 7.5 \\
\hline Semi-urban & 1 & 2.5 \\
\hline \multicolumn{3}{|c|}{ Relation to Patient } \\
\hline Wife & 12 & 30 \\
\hline Son & 16 & 40 \\
\hline Daughter & 2 & 5 \\
\hline Husband & 9 & 2.5 \\
\hline Father & 1 & 2.5 \\
\hline \multicolumn{3}{|c|}{ Type of Family } \\
\hline Nuclear & 10 & 25 \\
\hline Joint & 25 & 62.5 \\
\hline Extended & 5 & 12.5 \\
\hline
\end{tabular}


As per table no 2, majority of the caregivers belonged to the age group 31-40 years. The mean age of the caregivers was 43.825 years. Hindu caregivers (95\%) comprised the bulk of the study group. Majority of the caregivers $(90 \%)$ were from rural background, followed by $(7.5 \%)$ from urban and $(2.5 \%)$ from semi-urban region.Majority of caregivers $(67.5 \%)$ had duration of care of $1-4$ years while $32.5 \%$ caregivers' duration of care was of 5-8 years. $42.5 \%$ of the caregivers were illiterate. $95 \%$ of the caregivers were married while only $5 \%$ were single. Majority $(40 \%)$ of the caregivers were related as sons to the patients. Most of the caregivers (65\%) were male while $35 \%$ of the caregivers were female. Most of the caregiverswere from joint family $(62.5 \%)$, followed by $25 \%$ from nuclear family \&only $12.5 \%$ from extended family.

Overall $50 \%(n=20)$ of the sample experienced severe burden followed by $30 \%(n-=12)$ moderate burden, $15 \%(n=6)$ mild burden and only $5 \%(n=2)$ experienced no burden.

When distribution of caregivers by age with burden was explored, it was found that there was a significant difference in burden among the various caregivers by age with highest burden found in the age group of 61-70 years (mean 99.4). However, there was a no significant difference in burden among the various caregivers by religion. There was a significant difference in burden among the various caregivers by duration of care giving with highest burden found in 5-8 years of duration of care (mean 96.61).

There was a significant difference in burden among the caregiver by various educational level with highest burden found in illiterate (mean=95.53) and lowest among graduate caregivers (mean=63.50). There was a significant difference in burden among the various caregivers by locality with highest burden found in rural group (mean 87.19). There was a significant difference in burden among the various caregivers by type of family with highest burden found in nuclear family (Mean 90.92). There was no significant difference in burden among the various caregivers by marital status. There was no significant difference in burden among the various caregivers by sex. It was found that there was no significant difference in burden among the various caregivers by relation to patient.

Table No. 3 : Distribution of care givers with respect to predominant coping behavior

\begin{tabular}{|l|l|l|}
\hline \multicolumn{1}{|c|}{ Coping behavior } & $\begin{array}{c}\text { No of } \\
\text { caregivers }\end{array}$ & Percentage \\
\hline Confronting coping & 29 & 72.5 \\
\hline Distancing & 24 & 60 \\
\hline Self-controlling & 18 & 45 \\
\hline Seeking social support & 18 & 45 \\
\hline $\begin{array}{l}\text { Accepting } \\
\text { responsibility }\end{array}$ & 19 & 42.5 \\
\hline Escape avoidance & 12 & 30 \\
\hline $\begin{array}{l}\text { Planful problem } \\
\text { solving }\end{array}$ & 11 & 27.5 \\
\hline Positive reappraisal & 14 & 35 \\
\hline
\end{tabular}

All the caregivers in the study group used more than one style of coping behavior. As shown in table 3, most commonly used coping behaviors were "confronting coping" (72.5\%) followed by "distancing" (60\%), "Seeking social support" (45\%), "self-controlling" (45\%),"accepting responsibility" $(42.5 \%)$, "positive reappraisal" $(35 \%)$ and "escape avoidance" (30\%). "Planful problem solving" (27.5\%) was the least commonly used coping behavior.

Significant positive correlation $\left({ }^{*} \mathrm{p}\right.$ value $\left.<0.01\right)$ was observed between caregiver burden \& coping behaviors like "Confronting coping" \& "Escape avoidance". Statistical analysis revealed significant negative correlation ( ${ }^{*} \mathrm{p}$ value $\left.<0.01\right)$ observed between caregiver burden \& coping behaviors like" seeking social support", "accepting responsibility" and "planful problem solving". 


\section{Burden \& Coping in Caregivers of Persons with Dementia}

\section{CONCLUSION}

The various findings in our study have added to the growing evidence that Dementia can have serious consequences on families particularly the primary caregivers. This study demonstrates some of the important socio-demographic variables which have got influence on caregiver burden and therefore caregivers developed ways to alleviate burden, or more efficiently stated, cope. Results highlight the importance of improving the mixed coping skills in burdened caregivers. Therefore, the present study has given some insight in understanding the stress and burden among the caregivers of dementia patients.

\section{LIMITATIONS}

The study sample was relatively small. The study being hospital basedmay not reflect the true picture of the caregivers in the general population.Some of thecaregiver factors e g. Personality of the caregiver, cultural background, and psychological profile were not assessed and may have influenced the caregiver responses.Severity of the Dementia was not assessed and may have influenced the caregiver responses.

\section{REFERENCES}

(1) Richards S S, Sweet Robert A. Dementia. Benjamin James Sadock, Virginia Alcoit Sadock, Pedro Ruiz, Comprehensive textbook of psychiatry volume 1. ninth edition, 2009 : ch - 10.3, 1167-1171.

(2) Fadil H, Borazanci, Haddou E A B et al. Early Onset Dementia. International Review of Neurobiology 2009; $84: 245-262$.

(3) Dementia. The ICD - 10 classification of Mental and Behavioural Disorders. World Health Organisation, Geneva 2007 : 44-46.
(4) Seeley William W, Miller Bruce L Dementia Longo, Fauci, Kasper, Hauser, Jameson, Loscalzo, Harrison"s Principles of internal medicine, volume 2, 18th edition 2011; ch - $371: 3300$

(5) Murray CJL, Lopez AD, Mathers CD. The Global Burden of Disease 2000. World Health Organization 2001; 1-57

(6) Ferri CP, Prince M, Brayne C, Brodaty H, Fratiglioni L, Ganguli $\mathrm{M}$ et al. Global prevalence of dementia : A Delphi consensus study 2005; 366 (9503) : 2112-2117.

(7) Prince M, Jackson J.World Alzheimer Report 2009. Alzheimer's Diseases International 2009; 1-2 : 1-96.

(8) Prince M, Ferri CP, Acosta D, Albanese E, Arizaga R, Dewey $\mathrm{M}$ et al. The protocols for the 10/66 dementia research group population-based research programme. BMC Public Health 2007; $7: 165$.

(9) Prince M. Methodological issues for population-based research into dementia in developing countries: A position paper from the 10/66 Dementia Research Group. International Journal of Geriatric Psychiatry 2000; 15(1) : 21-30.

(10) World Health Organization. World Health Report 2002. Reducing Risks, Promoting Healthy Life Geneva : WHO 2002.

(11) 10/66 Dementia Research Group. Care arrangements for people with dementia in developing countries. Int J Geriatr Psychiatry 2004; 19 : 170-77.

(12) Dewey ME, Saz P. Dementia, cognitive impairment and mortality in persons aged 65 and over living in the community : a systematic review of the literature. International Journal of Geriatric Psychiatry 2001; 16(8) : 751-761.

(13) Shaji KS, Run Kishore NR, Praveen LK, Prince M. Revealing a hidden problem. An evaluation of a community dementia case-finding program from the Indian 10/66 dementia research network. International Journal of Geriatric Psychiatry 2002; 17(3) : 222-225.

(14) Branch, Lawrence G and Alan M Jette. A Prospective Study of Long - Term Care Institutionalization among the Aged." American Journal of Public Health 1982; 72(12) : 1373-1379.

(15) Thara R, Padmavati R, Shubakumar, Srinivasan L. Burden assessment schedule instrument to assess burden on caregivers of chronic mentally ill. Indian J. Psychiat 1998; $40(1): 21-29$.

(16) Lazarus RS, Folkman S. Stress, appraisal and coping 1984; $6: 141-143$

(17) Lazarus RS. Coping theory and research : past, present and future. Psychosomatic medicine 1993; 55 : 234-247. 